\title{
Organization of standardization work planning in an industrial enterprise
}

\author{
Daria Emelianova ${ }^{1}$, Natalia Kliuchareva ${ }^{1,{ }^{*}}$, Sergey Kolesnichenko-Yanushev ${ }^{1}$, \\ and Andrey Yakovlev ${ }^{1}$ \\ ${ }^{1}$ Peter the Great St. Petersburg Polytechnic University, Polytechnicheskaya str., 29, 195251, St. Pe- \\ tersburg, Russian Federation
}

\begin{abstract}
The paper considers the methodology for organizing information support planning at the main stages of a product life cycle. If used, the methodology will help minimize risks of counteragents' noncompliance with contractual obligations. The research study is aimed at substantiating the ways, techniques, and methods of building an effective information support management system of an enterprise through creating an adaptive system for standardization work planning. When preparing the materials suggested in the paper, such scientific research methods were used as: analyzing the information needs of an enterprise, simulating a short-term information support planning process, pooling the experience in organizing standardization work in industrial enterprises involved in single-piece and serial production, as well as the principles of consistency and comprehensiveness of information support planning. As a result of the conducted research study, the following ones are proposed: a methodology for forming a Standardization Action Plan in an enterprise (organization); ways and methods for adapting the Standardization Action Plan to changing production conditions; ways to monitor the realization of actions envisaged in the Plan; the rules for evaluating the effectiveness of the information support system of an enterprise. The general methodology of information support relies on a principle of building quality management systems that implement the Deming Cycle.
\end{abstract}

\section{Introduction}

The main objectives of information support on standardization documents in an industrial enterprise (organization) is timely and thorough provision of relevant regulatory documents. In order to purchase regulatory documents on a regular basis, maintain their life cycle and provide information support for deliveries and product life cycle, the following tasks have to be solved: different types of information should be categorized in the enterprise, the notion of a marketing information system should be defined, methods should be selected to evaluate the efficiency of information support in the enterprise and a model of an efficient management information system should be created [1]. It is possible to solve the above

\footnotetext{
*Corresponding author: klucharevaN@yandex.ru
} 
tasks successfully in case regulatory documents are provided in a synchronized way with the terms of contract obligations of the enterprise (organization).

Today the national standard of the Russian Federation GOST R 1.15-2009 'Standardization in the Russian Federation. Company standards department. Rules of organization and function', the issues related to the organization of standardization work planning in the Russian Federation are prescribed in detail only at the national level of standardization work planning.

Intercountry standards GOST 1.15-85 'State standardization system. The procedure for checking the revision, amendment and repeal of standards', GOST 1.20-85 'State standardization system. The procedure for introducing standards', Regulative Document RD 50335-82 'Methodological guideline. Developing the standardization plans of associations (enterprises). General provisions', which regulate the procedure for planning and implementing standardization work, have been cancelled. Currently the problem of innovative development of Russia is determined as a low level of technological innovativeness of the industrial sector. The share of industrial enterprises that develop and introduce technical innovations does not exceed $10 \%$, while the share of innovative products in the total output of industrial production in 2014 amounted only to $7.8 \%$ [2]. That is why it is essential and desirable to share methodological materials and practical experience in organizing standardization work planning.

This paper discusses methodological approaches to organizing standardization work planning and makes proposals on its improvement.

One of the most important problems of effective management in organizations is day-today cost management, which is aimed at obtaining the planned economic benefits from ordinary transactions. Today there is a serious concern that the stakeholders of individual organizations cannot play a full-fledged and active role in standardization projects because their resources are limited [3].

Given a considerable size of the information support costs that enterprises bear (cost of purchase, development, update of regulatory documents, staff training, purchase and use of electronic information systems), and the liability for non-compliance of user (license) agreements by the employees, information support should meet an important condition and prevent risks arising during purchases and in the process of use, development and update of regulatory documents. Analyzing the approaches to identifying and preventing risks discussed in [4], the results of practical experience in contractual work on information support of an enterprise, the following possible risk can be formulated:

- late and incomplete deliveries of external regulatory documents;

- late update of local regulatory documents and their late communication to the users;

- delayed and incomplete financing of the purchase of regulatory documents and their translation from foreign languages;

- poor quality of translation, including unauthorized translation of regulatory documents from foreign languages;

- inability of employees in enterprises and organizations to apply regulatory documents;

- application of out-of-date regulatory documents or incorrect use of regulatory documents (non-compliance with the requirements of regulatory documents) due to workers' incompetence or inadequacy of the infrastructure in an enterprise (organization) despite the requirements of regulatory documents).

In order to organize work on information support of an enterprise (organization) and minimize the above risks, it is important to create an information support system and organize its effective application.

Standardization work planning in an enterprise (organization), being a major condition for efficient management of the enterprise's information system, represents a part of the 
production planning system and must be consistent with the relevant plans for R8D work, plans for the manufacture and delivery of products (or provision of services).

Given that one of the key requirements for an information support system is that information support should be given in due time for manufacturing products (or providing services), the period of production planning (commonly, 1 year) should be chosen as a rational target period. Depending on the type of products (work, services) realized by an enterprise (organization), the target period can be prolonged up to three to five years.

In this case it is recommended that the standardization program should be elaborated with further formation (within the standardization program) of annual standardization action plans. Such an approach is good for coordinating the standardization plans with the financial plans of an enterprise (organization).

The standardization subdivision (department) of an enterprise has to form the programs (plans) and carry out standardization work in the organization for the next year and/or a longer time.

Standardization work planning includes the following several major processes:

- forming a standardization action plan;

- carrying out work according to the standardization plan;

- controlling fulfilment of the standardization action plan;

- assessing the efficiency of information support planning, and improving the planning system.

Let us see in more detail the procedure for implementing the major stages of standardization work planning in an enterprise (organization).

\section{Materials and methods}

Today many scientific publications, for example, those by Dr. Peter Hatto [3], Trieu C. Chieu ; Thao Nguyen ; Sridhar Maradugu [5], C. Wang and D. Tsai [6], are dedicated to the importance of building information support systems in enterprises. It is predetermined by the large volumes of regulatory documents in the field of standardization and technical regulation, which are used in production.

In order to form a methodology of information support of an enterprise, a method of information support structure synthesis has been applied. The process approach and application of the Deming cycle allowed us to organize post-transaction control of the standardization work planning processes. The structure of a standardization action plan of an industrial enterprise was formed through modelling.

\section{Results}

\subsection{Forming a Standardization Action Plan in an enterprise (organization)}

\subsubsection{Standardization work planning}

Standardization work planning starts with sending notifications to the subdivisions of an enterprise (organization) about the need to prepare and submit to the standardization department (to the person in charge) applications for information support for the target period.

Notifications (memos) about the need for submitting applications for information support to be included in the Standardization Plan of the enterprise should be sent to the production subdivisions (business units) before financial planning operations has started in the enterprise (organization). 
The applications sent by the business units to the standardization department (to a person in charge of standardization) can include the following types of requirements:

- to draw up new local regulatory documents;

- to update local regulatory documents:

- to purchase external regulatory documents (national or foreign ones);

- to check-up whether the requirements of regulatory documents are met;

- to educate the company employees on the issues of using standardization documents (including local and external regulatory documents).

The applications obtained from the subdivisions have to be analyzed and assessed in terms of the resources available and specialization of the subdivisions highlighted as potential performers of the standardization work.

Applications for the purchase of external regulatory documents must be assessed to see if they correspond to the expected costs of their purchase and the amount of money intended to be allocated to the standardization department (person in charge) of the enterprise (organization).

Motivation is a very important condition for the acceptance of applications from the subdivisions to be included in the Standardization Action Plan.

Every application from a subdivision must be substantiated before it can be included in the Standardization Action Plan.

Applications can be considered as substantiated if:

- the regulatory document is included in the terms of an agreement (contract) for the manufacture (delivery) of products (provision of services, performance of work) with a counteragent;

- the local regulatory document has become partially or completely obsolete;

- the external regulatory document has become partially or completely obsolete;

- the level of company employees' competence (competences) is insufficient;

- there are non-conformities (product defects, rejections) caused by non-compliance with regulatory documents in product manufacture, service provision, organized interaction between the subdivisions when the process approach is applied in the enterprise (organization).

An important condition for the applications to be reasonably included in the Standardization Plan of the enterprise (organization) are the terms of work and the responsible parties within the Standardization Plan. Given that participating in the work within the Standardization Plan implies that the human resources of the responsible subdivision will be involved, an applicant can suggest that either the workers from his own department should be carrying out the work or the employees from another department who have to carry out the work according to the existing decree on the subdivision and their job descriptions.

Based on the resource analysis and reasonability of proposals and applications, the standardization department (the person in charge) forms a draft of the Standardization Action Plan for the target period (next year). Table 1 presents a typical form of the Standardization Action Plan of an enterprise (organization). 
Table 1. A typical form of the Standardization Action Plan of an enterprise (organization).

\begin{tabular}{|c|c|c|c|c|c|}
\hline № & Type of work & $\begin{array}{l}\text { Subdivision } \\
\text { - work } \\
\text { performer }\end{array}$ & $\begin{array}{l}\text { Time of work } \\
\text { performance }\end{array}$ & $\begin{array}{l}\text { Time consump- } \\
\text { tion of work } \\
\text { (normal hours) } \\
\text { (Purchase costs, } \\
\text { rub.) } \\
\end{array}$ & Note \\
\hline $\begin{array}{l}1 \\
1.1\end{array}$ & $\begin{array}{l}\text { Development of new regulatory } \\
\text { documents_(designation, name) }\end{array}$ & & & & \\
\hline 2 & $\begin{array}{l}\text { Revision (repeal) of current regula- } \\
\text { tory documents } \\
\text { (designation, name) }\end{array}$ & & & & \\
\hline $\begin{array}{l}3 \\
3.1 \\
\end{array}$ & $\begin{array}{l}\text { Checking compliance with the re- } \\
\text { quirements of regulatory documents } \\
\text { (designation, name) }\end{array}$ & & & & \\
\hline $\begin{array}{l}4 \\
4.1 \\
\end{array}$ & $\begin{array}{l}\text { Training the company employees } \\
\text { (name of the subdivision) on the } \\
\text { subject: }\end{array}$ & & & & \\
\hline $\begin{array}{l}5 \\
5.1 \\
5.3\end{array}$ & $\begin{array}{l}\text { Purchase of regulatory documents } \\
\text { Purchase of national regulatory } \\
\text { documents } \\
\text { (designation, name) } \\
\text { Purchase of foreign regulatory doc- } \\
\text { uments } \\
\text { (designation, name) }\end{array}$ & & & & \\
\hline
\end{tabular}

\subsubsection{Approving the draft of the Standardization Action Plan}

The draft of the Standardization Action Plan has to be sent to all interested subdivisions of the enterprise (organization) for approval.

When the draft is sent, an important condition for approving the Standardization Action Plan is to stipulate the deadline for the approval and consideration of proposals (in case there are any) from the subdivisions. Given that the draft of the financial plan of the enterprise (organization) has usually been formed at this stage of the Standardization Action Plan, it is important to inform the subdivisions about the limitations on purchasing external regulatory documents and the expected time of their delivery to the enterprise.

When the work on the approval of the draft of the Standardization Action Plan is carried out, reasonable additional proposals of the subdivisions must be considered in the draft and the Standardization Action Plan must be presented to the head of the enterprise (organization) (quality assurance director, deputy quality assurance director).

Copies of the approved Standardization Action Plan of the enterprise (organization) must be sent to all interested subdivisions of the enterprise, and presented to the executives of the enterprise (organization) so as to ensure execution and control.

Changes should be introduced in the Standardization Action Plan of the enterprise, as a rule, in the following cases:

- new agreements (contracts) are signed or changes are introduced in the current agreements (contracts) for the design, manufacture, or servicing of the enterprise's products;

- according to the results of audit check-ups of the enterprise's management systems;

- innovative technologies are introduced. 
Changes to the content of the Standardization Action Plan can be included in the Supplement to the Standardization Action Plan and have to be approved by the interested subdivisions and by the head of the enterprise (a person who is a holder of a letter of attorney for approving the Standardization Action Plan).

\subsection{Work performance under the Standardization Action Plan}

The approved Standardization Action Plan presented to the enterprise's subdivisions has to be fulfilled by the employees in the subdivisions of the enterprise (organization), in accordance with the stipulated terms of the actions.

In case there are unforeseen circumstances related to the inability or inexpedience of carrying out the work, according to the Standardization Plan, the head of the subdivision which is to carry out the work has to prepare and send a relevant notification to the standardization department (to the person in charge) substantiating the reasons why the work has to be cancelled or why the deadlines should be changed.

The following ones can be good reasons why it can be decided to introduce amendments to the Standardization Action Plan:

- there is change in the terms of a contract for the manufacture (delivery) of product (provision of services);

- there is change in the organizational structure of the enterprise (organization);

- there is change in the infrastructure;

- there is change in the technology processes of product manufacturing or delivering (provision of services).

Following the results of the Standardization Action Plan, it is advisable to prepare a report on the work carried out with substantiation why some items of the Standardization Plan has to be prolonged.

The report on the fulfillment of the requirements of the Standardization Action Plan must present the following information:

- the performance of the Standardization Action Plan;

- the list and reasons why some work has not been carried out;

- the list of work suggested for transfer in the plans of the next target period;

- proposals on improving standardization work planning.

The report must be presented to the executive of the enterprise. Copies of the report must be sent to all interested subdivisions.

It is advisable that the outcomes of the Standardization Action Plan should be used as one of the performance indicators for the year.

\subsection{Control over fulfillment of the Standardization Action Plan}

It is advisable that the head of the standardization department (person in charge) of the enterprise (organization) should be responsible monitoring the work to be carried out.

The results of the work carried out according to the Standardization Action Plan should be assessed monthly by the head of the standardization department (person in charge) of the enterprise.

The information should be given to the interested subdivisions, the subdivisions involved in carrying out the work and the head of the enterprise (organization).

Our experience in how monitoring of the fulfillment of the Standardization Action Plan should be organized allows us to formulate a certain sequence of control:

- an anticipating notification of the work performer about the approaching deadline; 
- communication with the work performer to provide methodological support for drawing up draft regulatory documents;

- activation of communication between the interacting subdivisions when the work is carried out, setting up temporary working teams;

- monitoring the process of contract drafting and approval for the purchase of external regulatory documents;

- monitoring the process of contract drafting and approval for the translation of external regulatory documents;

- initiating and organizing consensus meeting in case there are contradictions between the workers of the interested subdivisions and the developers of the drafts of local regulatory documents.

The work performer is informed that the deadline of the work is over according to the Standardization Action Plan, as a rule, with an electronic or paper memo, sent to the head of the subdivision responsible for the fulfillment of work.

The memo can contain a reminder of the deadlines and possible risks in case the work included in the Standardization Action Plan of the enterprise (organization) is not carried out.

Interacting with the work performer to provide methodological support of regulatory document drafting or updating implies consulting with the developers of local regulatory documents, and presenting information about the current external regulatory documents relevant for the controlled unit described in the draft document.

When the work stipulated in the Standardization Action Plan is organized through setting up temporary creative teams that include employees of several participating subdivisions, a mandatory condition is that responsible work performers and a project manager should be appointed.

The process of drafting and approving a contract for the purchase (technical translation) of external regulatory documents poses the following possible risks:

- missing the deadlines set for the approval and signing;

- incorrect drafting of the contract.

- The following ones can be suggested as effective ways to eliminate these problems:

- making sure that draft contracts are drawn up in due time;

- organizing legal analysis;

- educating the employees of enterprises (organizations) involved in contract drafting;

- applying an automated electronic system for approving draft contracts.

An automated life cycle of a contract can significantly reduce the time enterprises need to sign agreements (contracts). The final benefit of this approach is that the processes of contract life cycle speed up, productivity increases, costs go down, potential contract errors and failures reduce to a minimum and the requirements are better complied with [5].

Many organizations "believe that if they focus exceptionally on people, technologies or methods, they can manage knowledge." Such a strategy will not allow a company to maintain its competitive advantage. For effective operation, organizations should create conditions for accountability and transparency [7]. So it is recommended that the work on educating the employees of the enterprise (organization) within the Standardization Action Plan should be monitored in cooperation with the workers of the subdivisions responsible for organizing staff training by checking that the study programs are fulfilled and that their contents meet the objectives of staff training. An important tool of control is monitoring the notes (reporting documents, logs, academic records). When carrying out the work envisaged by the Standardization Action Plan, it is advisable to apply the rules of the process approach to build up an information support system, and the Deming cycle, when each process is executed according to the plan. 


\subsection{Evaluating the efficiency of work on information support planning}

Information efficiency is determined through the volume of information that is necessary to ensure coordination and motivation processes. The author of paper proposes four strategies of organizational design aimed at increasing information efficiency. Two of these strategies focus on increasing the capability of an organization to process information and to create information systems stimulating information exchange.

Advocating the solution to the problem of information support of an enterprise discussed in the paper of Doctor of Technical Sciences Yu. A. Zelenkov (the author of paper), the following ones should be referred to as the main performance indicators of information support planning of an enterprise (organization):

- no missing deadlines on R\&D work caused by late information support;

- no poorly-timed purchase of materials, semi-finished products and component parts due to late information support;

- no violated obligations under contracts for the manufacture (delivery) of products, provision of services due to late information support;

- no unconformities (defects, rejections) of products (service provision outcomes) during technological processes and use due to the lack of regulatory documents, application of out-of-date regulatory documents;

- no failures to comply with the due date of customs-clearance procedures due to late information support [8];

- no substantiated claims of developers, distributors on the facts of violated terms of license agreements and copyrights when regulatory documents are applied [9].

\section{Discussion}

The methodology of standardization work planning in an industrial enterprise proposed in this paper focuses on the concept implemented by the quality management system of an enterprise. Being a management subsystem in an enterprise, it is oriented on the interests of the user of the products manufactured by the enterprise with indication of the ways to prevent the expected risks. The process of regulatory support planning, as a constituent process of the enterprise's quality management system ensures that the terms of the contracts for the delivery of products to the users are complied with in due time.

\section{Conclusion}

1. A verbal model of a standardization work planning system is suggested in order to create an information support system.

2. A methodology is proposed to form a standardization action plan. It considers the production needs and the requirement for approval with the representatives of the interested subdivisions.

3. Risks that can arise due to a poor quality of information support are formulated and methodological guidelines are provided to prevent them from happening.

4. Organizational measures are suggested to set up temporary creative teams from the employees of several participating subdivisions within which the persons in charge of work performance and the project manager are appointed.

5. The procedure for amending the approved Standardization Action Plan of an enterprise and the methodology for monitoring its implementation are formulated.

6. A form for drawing up a Standardization Action Plan of an enterprise is suggested. 


\section{References}

1. S. Ashmarina, A. Zotova, Economic Annals-XXI 160(7-8), 51-55, (2016). DOI: $10.21003 /$ ea.V160-10

2. N. Glushak, O. Glushak, Z. Shuklina, T. Gerashchenkova, SHS Web of Conferences 28, 01041, 1-5, (2016). DOI: 10.1051/shsconf/20162801041

3. P. Hatto, Directorate-General for Research Industrial Technologies, (2010) https://www.iec.ch/about/globalreach/academia/pdf/academia_governments/handbookstandardisation_en.pdf.

4. Y. Tikhomirov, Law and modern states 6, 9-24, (2017). DOI: http://dx.doi.org/10.14420/ru.2017.6.1.

5. C.C. Trieu, N. Thao, M. Sridhar, K. Thomas, IEEE International Conference on Services Computing, 613-620, (SCC 2007). DOI: 10.1109/SCC.2007.25

6. C. Wang, D. Tsai, 43rd Annual 2009 International Carnahan Conference on Security Technology, 265-267, (2009). DOI: 10.1109/CCST.2009.5335527

7. Y. Johnathan, Online Journal of Applied Knowledge Management 1(2), 44-55, (2013). https://www.researchgate.net/publication/313656700_Legal_and_ethical_issues_of_em ployee_monitoring

8. Y.A. Żelenkov, Business Informatics 2 (40), 25-32, (2017). DOI: 10.17323/19980663.2017.2.25.32.

9. S. Prilliman Jennifer, SSRN Electronic, (2008). DOI: 10.2139/ssrn.1825175 